\title{
The application of methacrylate resin and the derivation as restorative material of damaged tooth tissue
}

\author{
Adioro Soetojo \\ Department of Conservative Dentistry \\ Faculty of Dentistry Airlangga University \\ Surabaya - Indonesia
}

\begin{abstract}
The application of methacrylate resin and the derivation (composite resin and dentin bonding) in clinical conservative dentistry has been widely developed. This material could be used to restore class I-V cavity with good aesthetic due to the compatible color with tooth. Composite resin adhesion hydrophobically in enamel that is due to mechanic retention in the form of resin tags which penetrates into enamel porosity. Meanwhile hydrophilic dentin bonding adhesion due to the chemical reaction between functional groups of amino collagen with carbonyl in dentin bonding forming amide binding. In addition mechanical retention in which dentin bonding penetrating into nano inter fibrilar cavity then polymerized. The success of methacrylate resin adhesion restoration is decided by enamel porosity, wetting character of resin, wetting contact angle, good etching acid, optimal humidity of tooth surface, the accuracy of dentist during filling is done etc.
\end{abstract}

Key words: methacrylate resin, dentin bonding, HEMA, water chasing effect, nano filler resin, humidity

Correspondence: Adioro Soetojo, c/o: Bagian Konservasi Gigi, Fakultas Kedokteran Gigi Universitas Airlangga. Jln. Mayjend. Prof. Dr. Moestopo no. 47 Surabaya 60132, Indonesia.

\section{INTRODUCTION}

Methacrylate resin and the derivation or in term of conservative dentistry is called composite resin as restoration material which is frequently used due to the strength property such as the color is compatible with the tooth so it has good aesthetic, adequate hardness and strength, good adhesion on enamel and dentin.

This resin material was introduced by Bowen in 1960's under the name Bis-GMA which was mixed of Bisphenol A with glycydil methacrylate ${ }^{1-4}$ This resin is hydrophobic meaning it is only possible well adhered on relatively dry region such as enamel. Meanwhile for dentin tissue is generally wet due to the fluid from dentinal tubule, so the resin material would be difficult to perfectly adhere. Bowen resin was classified as conventional or traditional resin. ${ }^{5}$ By the development of science, some kinds of composite resin are produced such as micro filled composite resin, hybrid composite resin and recently it has been introduced nano filler resin. The latest resin has very small/soft filler therefore it has advantage such as hardness and strength is high because the filler particle is more compact, resin surface is smooth high precision and low contraction after polymerization process. ${ }^{6,7}$ At the clinic, the surface of resin restoration would stay longer in cavity is determined by several factors such as : the operator in cases of preparation design, manipulation and method of resin application, the method of acid etching as well as proper indication of restoration. On the other side, influential factor is from the patient, himself whether the patient pays attention to restoration of his tooth, proper eating habit and hygiene factor on tooth and oral cavity.

The purpose of this study is to describe clinical use of methacrylate resin and the derivation as restoration material of tooth decay, adhesive mechanism on tooth surface and the failure which occurs in adhesive process.

\section{Adhesive resin on tooth structure}

Adhesion process of restoration material on tooth structure is complex including methacrylate resin. ${ }^{1,3}$ Many factors could contribute the failure of resin adhesion on tooth surface, such as whether fluor solution has never been applied in tooth preparation in which it could reduce resin wetting character, the presence of smear layer on tooth surface in which smear layer is debris leftover during cavity preparation or tooth cutting for sample preparation, non homogeneous tooth composition, very different component of organic and inorganic in enamel or dentin. A restoration which could adhere on organic part is not sure to be able to adhere on inorganic part. In contrast, saliva or blood contamination on tooth surface. Dentin is a tissue which is always wet due to dentinal tubule. Bis-GMA resin could not adhere on dentin due to hydrophobic nature. Meanwhile HEMA dentin bonding because of hydrophobic nature, could adhere in dentin tissue, even though the amount of water in dentin is another consideration, too much water content would distribute HEMA adhesion on dentin. ${ }^{3}$

Physical adhesion of resin is correlated with tags i.e. adhesive resin penetrates into porous enamel after acid etching. ${ }^{1,3}$ Researchers observed the effect crystal 
orientation in enamel toward acid reaction, it is said that enamel dissolvent in acid is not always the same, depending on which direction acid would destroy the enamel and orientation of enamel prism ${ }^{3,8}$ and it is further stated that if enamel prism position is parallel with acid entrance so the structure of bee nest could be seen. It means that the most soluble part is the center of prism. In contrast, if the direction is perpendicular, so it would be seen like fibrous structure and the center of the prism would show more resistant to acid.

Resin adhesive process in dentin tissue is considered more complicated if it is compared with tooth enamel. Unlike in enamel, dentin is alive tissue which consists of about $60 \%$ inorganic in the form of hydroxy-apatite: $\mathrm{Ca}_{10}\left(\mathrm{PO}_{4}\right)_{6}(\mathrm{OH})_{2}: 30 \%$ organic and $10 \%$ water. $90 \%$ of organic material is collagen and the rest is non collagenous component. Most of collagen is type I and only a few of type V. Based on component of side chain ( $\mathrm{R}$ group in amino acid molecule], so collagen is classified into several types i.e. type I until type VII. Non collagenous matrix consist of phosphor-protein, proteoglicans, g-carboxy-glutamate which comprises of protein (such as: glaprotein), glycoprotein acid, growth factor and lipid. Collagen is protein bio polymer and arranged in triple helix (that fibers plaited each other) the binding between fibers is formed by the presence of hydrogen bond, so, the fiber becomes stiff and strong. Collagen fiber is generally in perpendicular direction toward dentinal tubule. Collagen in tissue usually functions as formation structure or strengthening tissue such as tendon, dermis, bone, dentinal tooth. Type I dentin collagen using no research material is usually a chain of amino proline, proline, glycin $\left[\mathrm{HN}-(\text { Pro-Pro-Gly) })_{5}-\mathrm{COOH}\right]^{3,8}$

Dentin elasticity is flexible bearing for the above enamel layer every location in dentin has different characteristic such as: the permeability in occlusal region on pulp horn is higher comparing with the center of tooth occlusal surface. Dentin in proximal part is more permeable than in occlusal region while dentin corona is more permeable than root region.

Adhesion of resin material in dentin is determined by the presence of smear layer formed during cavity preparation. The thickness of smear layer is between $0.5-0.6 \mu \mathrm{m}$ and should be previously removed in order that resin bonding material could bind fibril collagen to form hybrid dentin layer. ${ }^{8}$ Hybrid dentin as a mixed molecule between collagen with polymer resin and it is prepared in dentin sub surface. Which has been etched and also it is useful for monomer resin impregnacy in matrix. Open fibril collagen is not pure collagen material, however it is covered by some proteins such as non collagen protein and proteoglycan.

Energy of dentin surface is quite low, so, an effort should be made in order that tensile surface of primer material could be compatible with dentin surface. In this case if the fluid could flow freely on solid surface, so, tensile fluid surface should be lower than energy of free surface of solid material, if the fluid could wet the whole solid surface, therefore this condition is called wet the surface. Wetting capacity depends on contact angle formed by the fluid with substrate surface.

At present, the exhaustion of some hybrid composite products is less $20 \mu \mathrm{m}$ every year ${ }^{5}$. In this case it is almost similar with the mean exhaustion of amalgam is $10 \mu \mathrm{m}$ per year. Even though it is necessary to consider the advantage of new composite restoration which would be observed in short time that is about five years.

\section{Nano filler composite}

It is not different from other composites, nano filler composite is generally based on Bis-GMA, urethane dimethacrylate, triethyleneglycol dimethacrylate and etc. due to very small sized filler, this composite has good physical-mechanical nature i.e. hardness, strength, smooth resin surface, accurate presition, and more easily manipulated. ${ }^{6,7}$ The size of filler particle is $1-25 \mathrm{~nm}$ and $\mathrm{CaCO}_{3}, \mathrm{SiO}_{2}$, glass particle, boron, colloidal silicon are usually used.

Some researchers have done a study on $\mathrm{SiO}_{2}$ was heated with 5\% sodium peroxodisulfate solution, that followed by acetone cleansing. Pretreatment process of coupling silane was then observed using X-ray, photoelectron spectrometry. The result is better composite in wear character and fatigue resistant. $^{7}$

\section{Dentin bonding material}

In caries case which has involved dentin or cementum such as class $\mathrm{V}$ cervical erosion therefore filling with dentin bonding material is necessary. This case frequently occurs in elderly patient correlated with increasing of gingival retraction.

Dentin bonding adhesion in dentinal tissue could be chemical or physical mechanical bond. ${ }^{1,8}$ Chemical bond occurs due to the presence of reaction between functional group of carbonyl dentin bonding with type I amino collagen in dentin. Meanwhile physical-mechanical bond due to the presence of dentin bonding liquid penetrate into nano space inter fibriler, mechanical retention is tags that entering dentinal tubule and Vander Walls bonding between both material. ${ }^{1,2,3}$

Dentin bonding material is usually based on three essential components i.e. primer, coupling agent and sealer, in this study, primer material is called dentin conditioner which consisting of acid. On reference or in daily term, coupling agent is also called primer while sealer functioning as dentin sealer, in which the liquid would flow into dentinal tubule. ${ }^{2}$ Several years ago researcher believed that dentin bond was capable to form chemical bond with organic or inorganic group in dentin. This molecule could be described as $\mathrm{M}-\mathrm{R}-\mathrm{X}$ molecule in which $\mathrm{M}$ is methacrylate, $\mathrm{R}$ is spacer such as hydrocarbon chain and $\mathrm{X}$ is functional component which is useful to attach on dental tissue. During polymerization process, methacrylate group would react with resin forming chemical bond between resin and dentin., 
Dentin bonding material was firstly introduced in 1950's and it was called first generation of dentin bonding the composed active material is glycerol-phosphoric acid. However, the weakness of this material is shrinking during polymerization and high expansion of thermal coefficient. In second generation which was produced in 1970's, this material consisted of NPG-GMA (mix of N-phenylglysin and glycydil methacrylate). In clinical use it was seemingly lack of chemical binding between dentin bonding with dental tissue. In early 1980 the third generation was introduced this resin was based on halophosphorous ester of unfilled resin such as: Bis -GMA and HEMA (2 hydroxyethyl methacrylate). Chemically, resin adhesion with dentin calcium, in which interaction ion process occurs between phosphate group and dentin calcium. The adhesion is too weak to balance the strength therefore phosphonate ester binding with dentin would be hydrolyzed in oral liquid.

Up to now dentin bonding which usually produced is from seventh generation which is called self etching adhesive consists of acid material, primer, catalyst and adhesive resin. Therefore, in clinical application, the etching is not necessary. ${ }^{9,10}$ Long term resin adhesion in dentin is still doubtful, because cleansing is not done, therefore, the salt could not be removed. ${ }^{11}$ In which the leftover of residual smear layer is not only consisted of inorganic but also organic material, denatured collagen fibril and bacteria.

The adhesive strength of this material in dentin is lower compared with dentin bonding resin with total etched technique. ${ }^{12,13,15}$ Self etching adhesive has been proved incapable to close perfectly, in dentin surface and interface resin, dentin is shown porous. ${ }^{14}$

Some dentin bonding composed of multifunction monomer (primer or adhesive) with hydrophilic group to obtain good penetration and wetting. ${ }^{4,6}$ Hydrophobic nature would polymerize and bind with composite resin on the upper layer. Primer and adhesive is usually made in acetone dissolvent, alcohol or water, however, now days it is introduced in the form of solvent free, so it is not necessary drying before curing.

\section{HEMA as dentin bonding based material}

Numerous HEMA based dentin bonding material has been found on the market such as Scoth Bond Multi Purpose (SBMP), all bond, single bond, Clearfil SE bond etc. HEMA is widely used because of some advantages such as: the making process is relatively easy, and having strong endurance capacity due to additional preservative substance is generally used such as: hydroquinone, butylated hydroxy toluene (BHT) and relatively low viscosity. ${ }^{17,18}$

The formula of HEMA is $\mathrm{C}_{6} \mathrm{H}_{10} \mathrm{O}_{3}$ (Figure 1), molecular weight is 130 and the use as dentin bonding material usually mixed with water, ethanol, or acetone. However, bonding with acetone dissolving for prolonged storage is less stable because acetone is easily evaporated therefore it would disturb dentin bonding material's concentration. ${ }^{19,20}$

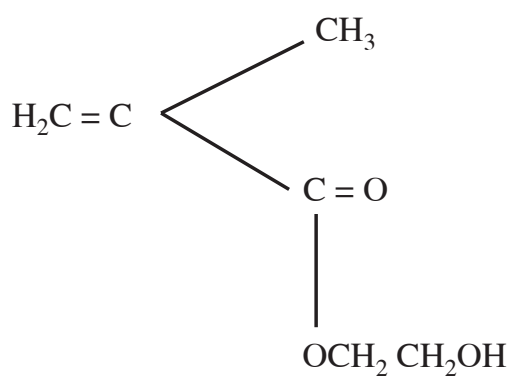

Figure 1. HEMA molecular structure $\left(\mathrm{C}_{6} \mathrm{H}_{10} \mathrm{O}_{3}\right){ }^{8}$

\section{DISCUSSION}

The application of methacrylate based resin (composite resin, dentin bonding) is widely used at the clinic. This material could be applied as restoration for class I, II, III, IV, and V caries. Composite resin is the main choice especially for restoration with aesthetic factor to be the main consideration, and composite resin is proper indication, even for posterior tooth cavity which is not too big.

Composite resin has many advantages, however, a dentist should be really careful and accurate during the treatment using this material. During acid etching period, operational part should be really dry, and should not be contaminated by water, saliva or blood, therefore rubber dam or saliva ejector is necessarily used. Moreover, the treatment using composite resin initiated by dentin bonding material needs more application steps.

At clinic, many patients were found with profound or cervical caries had involved many dentins, therefore treatments with dentin bonding material were needed. Some recent years, a lot of 6 and 7 generation of dentin bonding have been produced which are usually called self dentin bonding. Self etch means dentin bonding which is mixed with acid etching material. Clinically, self etch is very beneficial because acid etching step, cleansing and drying are not necessarily done. In fact, cleansing is useful to remove the residual salt which is formed as a result of chemical reaction between acid and hydroxy-apatite dentin. The left over salt on tooth surface could disturb resin adhesion to the tooth, therefore, restorative resin is easily released. In addition, other materials which are also left on dentin surface are smear layer, protein/collagen which are denatured and some bacteria. ${ }^{11,12}$ It was reported that material which is left on dentin surface in certain period of time could penetrate into pulp space as a result pulpitis would occur, therefore some researchers still hesitate to apply self etch for prolonged use. Researchers reported that the strength of total etching resin adhesion is higher comparing to self etch. ${ }^{12}$ The result of this study has proved that total etch dentin bonding adhesion (Voco, Excite) is significantly higher comparing to self etch (Xeno, Clearfil, LB) in $\mathrm{p} \leq 0,05 .^{21}$ 
Ideal adhesion between dentin bonding with collagen dentin could de reached if the humidity condition on dentin surface in optimal condition. ${ }^{21}$ Optimal humidity could contribute fibrilar collagen to be active and very permeable so the binding between both materials could easily occur. If collagen fibrilar is permeable, chemical reaction between amino collagen and carbonyl dentin bonding would take place and followed by amide bonding. Besides, hydrogen binding also happens between both of them and continued by the formation of functional group (such as: carbonyl group, hydroxy, carboxilate, amine and amide). ${ }^{22}$ In this condition, complex reaction also happens between collagen and dentin calcium.

In general, the success of dentin bonding adhesion in collagenous dentin depends on several factors i.e. low viscosity, type, concentration monomer, acid application as conditioner, temperature and humidity of adjacent collagen fibrilar. ${ }^{8,24}$ In vitro study was also performed on the effect of humidity on dentin bonding adhesion on dentin surface in which the humidity was $30 \%, 30 \%, 75 \%$, and $100 \% .^{25}$ It was reported that oral cavity humidity depends on whether rubber dam was used or not. If it was, the humidity was affected by humidity of dentist's practicing room i.e. $50 \% \pm$ at $23^{\circ} \mathrm{C}$, but if rubber dam was not used, the humidity was about $80 \%-94 \%$. The result in general shows increasing adhesion strength between dentin bonding with dentinal tooth simultaneously with increasing humidity, even though statistical analysis shows there is no significant difference. Further more, it is also proved that bonding with HEMA content has the highest adhesion strength comparing to other adhesive materials.

Another study used two kinds of material i.e. Scoth Bond Multi Purpose (consisting of $47 \%$ HEMA, $40 \%$ water and $13 \%$ polyalkenoat) and Clearfill SE Bond (consisting of HEMA, 10-methacryloyloxydecil-dihydrogen phosphate, alcohol), the humidity was: $30 \%, 50 \%, 65 \%, 80 \%$, and $95 \%$. The result has shown the increasing adhesion strength of both kinds of bonding in dentin correlated with decreasing humidity in adjacent dentin. ${ }^{26}$

The present study is also compatible with study done by Chiba et al. ${ }^{27}$ reported that adhesion strength dentin bonding would decrease correlated with increasing humidity used in the study in which the humidity was about $50 \%, 80 \%$, and $90 \%$.

The meaning of humidity is a condition correlated with water content in the adjacent material. Humidity according to American encyclopedia is the amount of the water vapor containing in atmosphere. It is known as relative humidity that is comparison between water vapor in the atmosphere and the amount needed to make it saturated (in percentage) at a certain temperature. In this case, it means that humidity in the adjacent collagen would affect chemical characteristic and physical collagen bonding. The change would affect collagen binding on HEMA which is applied in the upper part either physical-mechanically or chemically. As it has been previously mentioned that water molecule in the adjacent would be capable to contribute physical change in collagen it self.

Up to the present there is not any study on the effect of humidity on chemical binding between HEMA and collagen which is observed simultaneously with adhesion strength mechanically between both materials. Initiated by the previous study suggested that minimal humidity in oral cavity using rubber dam was $50 \%$, so the same study is done. The result shows that minimal humidity of oral cavity using rubber dam is $60 \%$ (similar with humidity of practicing room at $23^{\circ} \mathrm{C}$ ). This humidity of tropical countries in which it is higher than countries with cold climate. $^{21}$

Attaching or adhering two surface of solid materials is very difficult, ${ }^{1,2,3}$ even though with bare eyes both surface are smooth, but in microscopic level the surface is very rough, therefore if both surface are adhered, only the remarkable part is able to have adhesive contact, therefore, as a whole the contact field is not adequate and adhesion strength is low. Strain force of two molecules would occur if the distance between them is less than $0.7 \mathrm{~nm}$, higher than $0.7 \mathrm{~nm}$ would be very difficult. One of the ways to manage this problem is adding fluid in both surface. In order to obtain good adhesion, the fluid should be to flow and to wet the surface perfectly. In dentistry field, the capacity of adhesion to wet the surface is affected by several factors such as: the cleanness of the surface. Thin layer of oxidation on metal surface could hinder adherence of adhesive material including inorganic fluid of acid etching on dentin surface could increase wetting, surface roughness and contribute dentinal tubule opening. ${ }^{28}$

In order to know the capacity of adhesive material wetting the surface which would be adhered, so it could be calculated the contact angle between adhesive fluid and solid surface of the material interface area ${ }^{1,4}$ if adhesive molecule which could perfectly attract material molecule which would be adhered, so, adhesive fluid would wet the whole surface. In this way, wetting contact angle is $0^{\circ}$, however, if contact angle is big meaning the wetting capacity of adhesive material is bad (Figure 2).

The kind of dissolvent material in dentin bonding fluid would affect adhesive process. ${ }^{22,29}$ As we know, acetone fluid is easily evaporated, and depleting resin
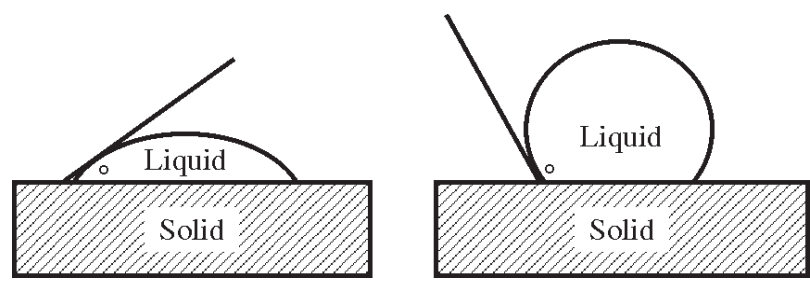

Figure 2. Wetting of, material surface (solid). ${ }^{1,4}$ Left, small contact angle $(\varnothing)$, good surface wetting. Right, big contact angle, bad wetting. 
solution layer so it would decrease viscosity. When the solution is polished on dentin surface, it would penetrate into nano space between collagen fibrilar then drive water molecule and next, it would evaporate, so, it would leave dentin bonding resin to bind collagen fibrilar. ${ }^{29}$ Acetone concentration would affect the thickness of bonding resin layer and the strain force. But the thickness of bonding resin will not correlate with strain force. ${ }^{29}$ The presence of cracking resin due to acetone evaporate, bad polymerization and low capacity/strength of strain of bonding resin (due to excessive amount of acetone). The other property of acetone is capable to drive water (water chasing effect), to increase vapor pressure of water especially water in adjacent collagen. It is proved that acetone ideal concentration is $37 \%$ of the weight, in this concentration, $\mu \mathrm{m}$ resin layer thickness and $63.5 \mathrm{MPa}$ strain force is obtained.

The study has been done and the result shows that the strain force in $60 \%$ humidity compared to $70 \%$ humidity, the number of water molecule is higher compared to $60 \%$ humidity, so the capacity of acetone to drive water molecule is higher and in this condition bonding resin would soon penetrate into collagen. ${ }^{21}$ The next chemical binding between resin and collagen is obtained and resin would penetrate into nano space interfibrilar forming mechanical retention. Finally the value of strain force in $60 \%$ (control), $70 \%, 80 \%$, and $90 \%$ humidity. Chemical interaction between bonding resin which is believed to be the mean strength of resin adhesion and dentin. ${ }^{22,27}$ It is stated that by wrapping of $\mathrm{N}-$ methacryloxy-amino acid (N-MAA) resin, the collapsed collagen would re-expand, develop collagen layer after acid etching and drying, so finally it would easily diffuse N-MAA solution into collagen. After polishing of N-MAA, significant increase of hybrid layer thickness until ten times higher and strain force would also increase. In fact the phenomena above is not supported by other experts. The thickness of hybrid layer has no correlation with strain force between resin and dentin. ${ }^{30}$

The conclusion is clinical use of methacrylate resin and the derivation (composite resin and denting bonding) could be used for restoration of class I-V caries. Adhesion resin in enamel and dentin depends on humidity, etching acid technique, wetting contact angle, resin dissolvent, and the accuracy of dentist during resin application.

\section{REFERENCES}

1. Anusavice KJ. Phillip's science of dental materials. $11^{\text {th }}$ ed Philadelphia: WB Saunders Co; 2003. p. 21-395.

2. Noort RV. Introduction to dental materials. $2^{\text {nd }}$ ed. EdinburghLondon, New York, Oxford: CV Mosby Co; 2002. p. 11-78.

3. Summitt JB, Robbins JW, Hilton TJ, Schwartz R. Fundamentals of operative dentistry. $3^{\text {rd }}$ ed. Chicago: Quintess Publ. Co, Inc; 2006. p. 183-242.

4. Craig RG, Powers JM, Wataha JC. Dental materials. Properties and manipulation. $8^{\text {th }}$ ed. Baltimore, Boston, Carlsbad: Mosby Inc; 2002. p. $57-78$
5. Baum L, Phillips RW, Lund M. Buku ajar operative dentistry. Tarigan, editor. $1^{\text {st }}$ ed. Jakarta: Penerbit Buku Kedokteran (EGC); 1997. p. 251-65.

6. Yu HJ, Wang L, Shi Q, Jiang GH. Study on nano $\mathrm{CaCO}_{3}$ modified epoxy powder coating. Progress in organic coating 2006; 5:296-300.

7. Shirai K, Yoshida Y, Nakayama Y. Assessment of decontamination methods as Pretreatment of silanization of composites glass filler. J Biomed Res 2000; 53:204-10.

8. Nakabayashi NP, Pashley DH. Hybridization of dental hard tissues. $1^{\text {st }}$ ed. Chicago IL: Quintess Publ Co, Ltd; 1998. p. 1-107.

9. Koibuchi H, Yasuda N, Nakabayashi N. Bonding to dentin with a self-etching primer. Dent Mat 2001; 17:122-26.

10. Zohairy AA, De Gee AJ, Mohsen M. Effect of conditioning time of self-etching primers on dentin bond strength of three adhesive resin cements. Dent Mat 2005; 21:83-93.

11. Harada N, Nakajima M, Pereira NR, Yamaguchi S. Tensile bond strength of a newly developed one-bottle self etching resin bonding systems to various dental substrates, Dent in Japan 2000; 36:47-53.

12. Moll K, Park HJ, Haller B. Bond strength of adhesive/composite combinations to dentin involving total and self etch adhesive. J Adhesive Dent 2002; 3:171-80.

13. Yoshiyama M, Tay FR, Doi J, Nishitani Y, Yamada T, Nakajima M. Bonding of self etch and total-etch adhesives to carious dentin. J Dent Res 2002; 81:556-60.

14. Tay FR, King NM, Chan K. How can nanoleakage occur in self-etching adhesive systems that demineralize and infiltrate simultaneously? J Adhes Dent 2002; 4:255-69.

15. Adioro $\mathrm{S}$. The fractographic analysis of three dentin bonding agents on tooth surface. Dental Journal (Majalah Kedokteran Gigi) 2006; 39(4):151-55.

16. Swift EJ, Wilder AD, May KN, Waddell SL. Shear bond strength of one-bottle dentin adhesives using multiple applications. Operative Dent 1997; 22:194-99.

17. Tay FR, Pashley DH. Aggressiveness of contemporary self-etching systems. Dent Mat 2001; 17:296-308.

18. Perdigao J, Lopes M. The effect of etching time on dentin demineralization. Restorative Dent 2001; 32:19-26.

19. Maciel KT, Carvalho RM, Ringle RD. The effect of acetone, ethanol, HEMA and air on the stiffness of human decalcified dentin matrix. J Dent Res 1996; 75:1851-58.

20. Leal JIR, Osorio R, Terriza JAH. Dentin wetting by four adhesive system. Dent Mat 2001; 17:526-32.

21. Adioro S. Kekuatan perlekatan antara bahan bonding HEMA dengan kolagen dentin pada berbagai kelembaban. Dissertation. Surabaya: Airlangga University; 2006. p. 66-9.

22. Xu J, Stangel I, Butler IS, Gilson DFR. An FT Raman Spectroscopy investigation of dentin and collagen surfaces modified by HEMA. J Dent Res 1997; 76:596-601.

23. Renzo MD, Ellis TH. Chemical reactions between dentin and bonding agents. J adhesion 1994; 47:115-21.

24. Brackett MG, Brackett WW, Haish LD. Micro leakage of class V resin composites placed using self-etching resins. Quintess Int 2006; 37:109-13.

25. Finger WJ, Tani C. Effect of relative humidity on bond strength of self-etching Adhesive to dentin. J Adhes Dent 2002; 4:277-82.

26. Besnault C, Attal JP. Influence of a simulated oral environmental on dentin bond strength of two adhesive systems. Am J Dent 2001; 14:367-72.

27. Chiba Y, Miyasaki M, Rikuta A. Moore BK. Influence of environmental conditions on dentin bond strengths of one application adhesive systems. Oper Dent 2004; 29:554-9.

28. Rosales JI, Marshall GW, Watanabe LG. Acid etching and hydration influence on dentin roughness and wet ability. J Dent Res 1999; 78:1554-9.

29. Cho BH, Dickens SH. Effect of the acetone content of single solution dentin bonding agents on the adhesive layer thickness and the micro tensile bond strength. Dent Mat 2004; 20:107-15.

30. Wang Y, Spencer P. Hybridization efficiency of the adhesive/dentin interface with wet bonding. J Dent Res 2003; 82:141-45. 